\title{
Elucidating esterification reaction during deposition of cutin monomers from classical molecular dynamics simulations
}

\author{
Otto V.M. Bueno, ${ }^{\text {a J. J. Benítez }}{ }^{\mathrm{b}}$ and Miguel A. San-Miguel ${ }^{\mathrm{a}}{ }^{*}$ \\ a Department of Physical Chemistry, Institute of Chemistry, University of Campinas - UNICAMP, \\ P.O. Box 6154, 13083-970 Campinas, SP, Brazil. E-mail: smiguel@unicamp.br \\ b Instituto de Ciencias de Materiales de Sevilla, Centro Mixto CSIC-Universidad de Sevilla, Avda, \\ Americo Vespuccio, 49 (41092)-Sevilla, Spain
}

\begin{abstract}
The structural behavior of some cutin monomers, when deposited on mica support, was extensively investigated by our research group. However, other events, such as esterification reaction (ER) are still a way to explore. In this paper, we explore possible ER that could occur when these monomers adsorb on support. Although classical molecular dynamics simulations are not able to capture reactive effects, here we show that they become valuable strategies to analyze the initial structural configurations to predict the most favorable reaction routes. Thus, when depositing aleuritic acid (ALE), it is observed that the loss of capacity to form self-assembled (SA) systems favors different routes to occur ER. In pure ALE bilayers systems, an ER is given exclusively through the $-\mathrm{COOH}$ and primary-OH groups. In pure ALE monolayers systems, the ER does not happen when the system is self-assembled. However, for disorganized systems, it is able to occur by two possible routes: $-\mathrm{COOH}$ and primary- $\mathrm{OH}$ (route 1) and $-\mathrm{COOH}$ and secondary- $\mathrm{OH}$ (route 2). When palmitic acid (PAL) is added in small quantities, ALE SAMs can now form an ER. In this case, ER occurs mostly through the $-\mathrm{COOH}$ and secondary-OH groups. However, when the presence of PAL is dominant, ER can occur with either of both possibilities, that is, routes 1 and 2.
\end{abstract}

\section{KEYWORDS}

Molecular dynamics; esterification reaction; self-assembly; aleuritic acid; palmitic acid 


\section{INTRODUCTION}

Fatty polyhydroxyacids $\left(\mathrm{C}_{16}, \mathrm{C}_{18}\right)$ are the building monomers of ubiquitous biopolyesters such as cutin and suberin in higher plants tissues [1]. Both constitute the fourth most abundant plant biopolymer in Nature after cellulose, hemicellulose and lignin. In addition to the natural abundance, their extraordinary barrier capacity has attracted the interest for the obtaining of synthetic mimetic polymers to replace hazardous and non-biodegradable petroleum derived materials $[2,3]$. Fatty polyhydroxyacids have been found to have the capability to self-assemble and self-esterify at ambient condition to form nanometer size particles named as cutinsomes [4]. Such nanoparticles have been detected in planta [5] and they can further aggregate and spontaneously polymerize at standard environmental conditions to form a continuous polyester layer, thus providing a plausible mechanism for in vivo cutin biosynthesis [6,7]. Such hypothesis is gaining recognition since analogous nanometer size structures have also been recently detected in the elucidation of the molecular architecture of suberin [8].

The structure of nanoparticles constituted by fatty hydroxyacid is primarily conditioned by intermolecular interactions. Those interactions have been studied by our group both theoretically and experimentally by the formulation of confined and geometrically well-defined systems such a self-assembled (SA) layers on flat inert surfaces.

Several analytical techniques such as atomic force microscopy (AFM) and scanning tunneling microscopy (STM) combined with molecular dynamics simulations, were essential to understanding the behavior of these monomers [9]. With these techniques, it was possible to show that the deposition of polyhydroxy acids leads to the formation of self-assembled bilayers (SABs) and monolayers (SAMs), depending on the presence and position of the functional groups $(-\mathrm{COOH}$, and $-\mathrm{OH})$ in the aliphatic chain.

The importance of these studies lies on the transference of this seminal knowledge to the design and manufacturing of layered biodegradable biomimetic materials with potential applications as, protective films for food and cosmetics packaging [10,11,12,13].

Therefore, to investigate other properties, in addition to the structural ones, the feasibility of the esterification reaction (ER) is of major importance for this purpose. Our first ER studies by attenuated total reflection Fourier transform infrared (ATR-FT-IR) spectroscopy, X-ray photoelectron spectroscopy (XPS) and molecular dynamics (MD) techniques in self-assembled (SABs) systems of aleuritic acid (ALE) bilayers show that the esterification reaction occurs as a consequence of the formation of SA [14]. However, in this preliminary study, it was not satisfactorily clarified experimentally whether the water detected originates from esterification, or 
from the environment. Our results from MD simulations suggested that it comes from esterification.

This reaction could be classified as a rare event since it would present a high activation energy barrier and requires catalysts to happen [15]. In this work, this possibility will be more explored by using MD simulations of different nanostructures observed in AFM images in pure ALE systems. Additionally, we also study mixed systems of ALE and palmitic acid (PAL) with different compositions (25:75 and 75:25\% of ALE:PAL). PAL molecule has only a terminal $-\mathrm{COOH}$, and when mixing with ALE modifies the capability of self-assembling, resulting in systems with different degrees of disordering, which constitutes an essential aspect in the understanding of the ER mechanisms.

\section{EXPERIMENTAL SECTION}

\subsection{AFM operation}

AFM images were obtained with a Nanotec Cervantes microscope (Nanotec, Spain) using either a long range $\left(70 \times 70 \mathrm{~m} \mu \mathrm{m}^{2}\right)$ scanner to check for reproducible sample preparation or a shorter one $\left(10 \times 10 \mu \mathrm{m}^{2}\right)$ to collect more accurate topographic data. Every sample was studied at four distant points using both scanners and images were acquired, processed and analyzed using the WSxM software. Scanners were calibrated using NT-MDT TGT01 and Nanosensors H8 gratings for (X-Y) and $Z$ directions, respectively.

The AFM microscope was operated in air in dynamic, contact and jumping modes. Dynamic is selected for height measurement because it exerts a minimal perturbation of the sample by the scanning probe. In this mode, silicon cantilevers (PPP-FMR Nanosensors) with nominal $75 \mathrm{kHz}$ resonance frequency and $2.8 \mathrm{~N} / \mathrm{m}$ force constant $(\mathrm{k})$ were used. The lever was oscillated $\left(\mathrm{A}_{0} \sim 90\right.$ $\mathrm{nm}$ peak to peak) at its free resonance frequency. The feedback signal was set to a $20 \%$ reduction of the free oscillation amplitude and both topographic and phase-shift images were recorded simultaneously. For additional friction and adhesion mapping, the AFM was operated in contact and jumping modes using $\mathrm{Si}_{3} \mathrm{~N}_{4}$ levers (TR400PSA Olympus, $\mathrm{k}=0.08 \mathrm{~N} / \mathrm{m}$ and RC800PSA Olympus, $\mathrm{k}=0.1 \mathrm{~N} / \mathrm{m}$, respectively) at low set points.

\subsection{Sample preparation}

Self-assembled layers of aleuritic (9,10,16 trihydroxyhexadecanoic, $\mathrm{TCl},>98.0 \%)$ acid were prepared from a $0.5 \mathrm{mM}$ solution in chloroform (Merck, 99.8\%) by spin coating. A $20 \mu \mathrm{l}$ drop was placed on top of a piece of freshly cleaved mica (muscovite) and spun at $40 \mathrm{rps}$ for 20 seconds. 
Samples were stabilized for 3-4 hours at RT inside a covered glass Petri dish before being transferred to the AFM microscope. For reproducibility, each preparation was repeated at least four times.

\section{COMPUTATIONAL METHODS}

Molecular dynamics (MD) simulations were carried out using the Classic DL_POLY [16] code in the canonical ensemble NVT [17]. The temperature was kept constant at $300 \mathrm{~K}$ by applying a NoséHoover thermostat [18]. The equations of motion were integrated by using the velocity-Verlet algorithm with a time step of $1.0 \mathrm{fs}$.

The $-\mathrm{CH}_{3}$ and $-\mathrm{CH}_{2}$ - groups were treated as pseudo atomic units using the CHARMM19 force field [19] (Figure 1 and equation 1). Lennard-Jones (LJ) and Coulomb interactions were truncated at 15 $\AA$ in our simulations. Periodic boundary conditions were applied along the $\mathrm{x}$ and $\mathrm{y}$ directions. The Ewald method with periodic boundary conditions in two dimensions was used to treat the electrostatic interactions. Computational box with lengths of $L x=60.0 \AA$ and $L y=34.6 \AA$ were considered to simulate all systems. The substrate was represented as a flat surface using two models: (1) a 12-3 Lennard-Jones type external potential (equation 2) and (2) a short-range homogeneous flat potential.

$$
\begin{aligned}
& E_{1}=\sum_{b} K_{b}\left[b-b_{0}\right]^{2}+\sum_{\theta} K_{b}\left[\theta-\theta_{0}\right]^{2}+\sum_{\varphi} K_{\varphi}\left[1+d \cos n \varphi_{0}\right]+\sum_{i, j} 4 \varepsilon_{i j}\left[\left(\frac{\sigma_{i j}}{r_{i j}}\right)^{12}-\left(\frac{\sigma_{i j}}{r_{i j}}\right)^{6}\right]+ \\
& \sum_{i, j} \frac{q_{i} q_{j}}{\epsilon r_{i j}} \\
& \text { Equation (1) }
\end{aligned}
$$

$E_{2}=\sum_{i, j} \frac{C_{12}}{\left[z-z_{0}\right]^{12}}-\frac{C_{3}}{\left[z-z_{0}\right]^{3}}$

Equation (2)

Where $\mathrm{C}_{12}$ and $\mathrm{C}_{3}$ parameters for $-\mathrm{CH}_{2}-,-\mathrm{CH}_{3}, \mathrm{C}$, and $\mathrm{O}$ were taken from the literature $[20,21,22]$, $z$ is the distance to the surface, and $z_{0}$ is a limit approach distance for each center. Further $b_{0}, \theta_{0}$, and $\phi_{0} / \phi_{i}$ are equilibrium bond length, bond angle, and dihedral angle, respectively. $K_{b}, K_{\theta}$, and $K_{\phi}$ are the corresponding constants, and $\mathrm{b}$ and $\theta$ are the actual bond length and bond angle, respectively. $\varepsilon_{\mathrm{ij}}$ and $\sigma_{\mathrm{ij}}$ decide the minimum and zero values of the van der Waals term, which is described by 12-6 Lennard-Jones (L-J) potential, and $r_{i j}$ is the distance between two particles with charges $q_{i}$ and $q_{j}$. L-J potential parameters between different crossed atoms were calculated using the Lorentz-Berthelot combining rules. In the short-range homogeneous flat potential model, the parameters were taken from the literature $[23,24,25]$ and the atoms were frozen for stability as recommended. 


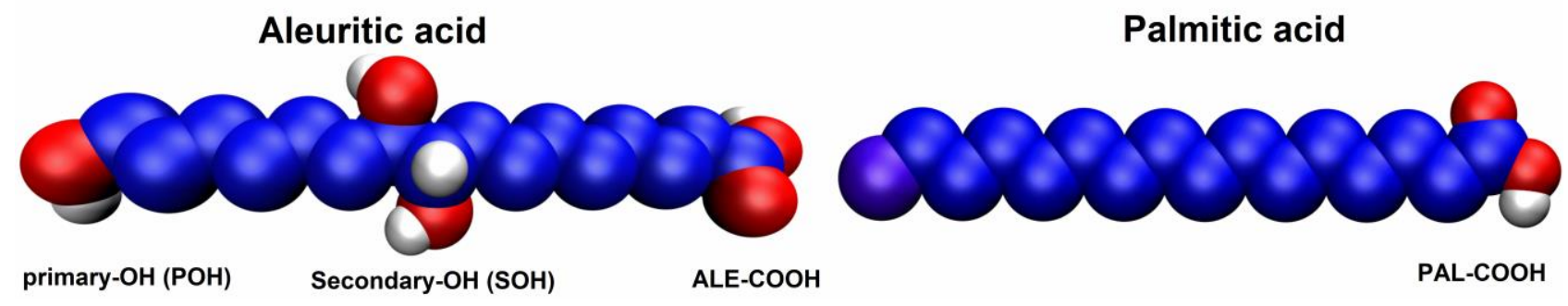

Figure 1. Representation of ALE and PAL molecules using the CHARMM19 force field.

A total of 10 systems were defined to model mixtures of ALE compositions in weigh of 25,75 and 100\%, named as 25:75, 75:25 and 100:00 (ALE:PAL), respectively. Based on experimental results, these systems were chosen as representative cases for (1) segregated, (2) dispersed, and (3) pure systems, respectively. Thus, initial configurations were constructed by placing a total of 96 molecules of ALE and/or PAL oriented vertically with the carboxylic group near the support.

For each of these compositions, in a hexagonal network, the dispersed (D), segregated (S) and pure (P) systems were built. For a 75:25 composition, two dispersed configurations, named H75D1 and H75D2, and two segregated configurations, denoted as H75S1 and H75S2, were established. Similarly, for a 25:75 composition, there are two dispersed (H25D1 and H25D2) and two segregated ( $\mathrm{H} 25 \mathrm{~S} 1$ and H25S2) systems. For pure ALE systems, monolayer and bilayer systems were defined and named as $\mathrm{H} 100 \mathrm{M}$ and $\mathrm{H} 100 \mathrm{~B}$. The nomenclature and details for each type of system are compiled in Figure $\mathbf{2}$.

The initial configurations, created with high structural tension, were submitted to a relaxation process using the 'zero' technique implemented in the DL_POLY code for 1 ns. Next, the equilibration process was carried out gradually at 100, 200, and $300 \mathrm{~K}$, during $1 \mathrm{~ns}$ for each temperature, and verifying that equilibrium was reached at each stage. Finally, all systems were simulated for $30 \mathrm{~ns}$. The structural properties were analyzed along the trajectory in the following intervals: (1) 9.5-10.0 ns, (2) 19.5-20.0 ns, and (3) 29.5-30.0 ns. Configurations were saved every 50 timesteps collecting 10000 configurations at each interval for statistical analysis. In all of those intervals, the behavior of the structural properties remained unaltered. For the analysis of hydrogen bonding ( $\mathrm{H}$-bond), it was considered the 10-30 ns trajectory. 


\section{Systems 25:75}

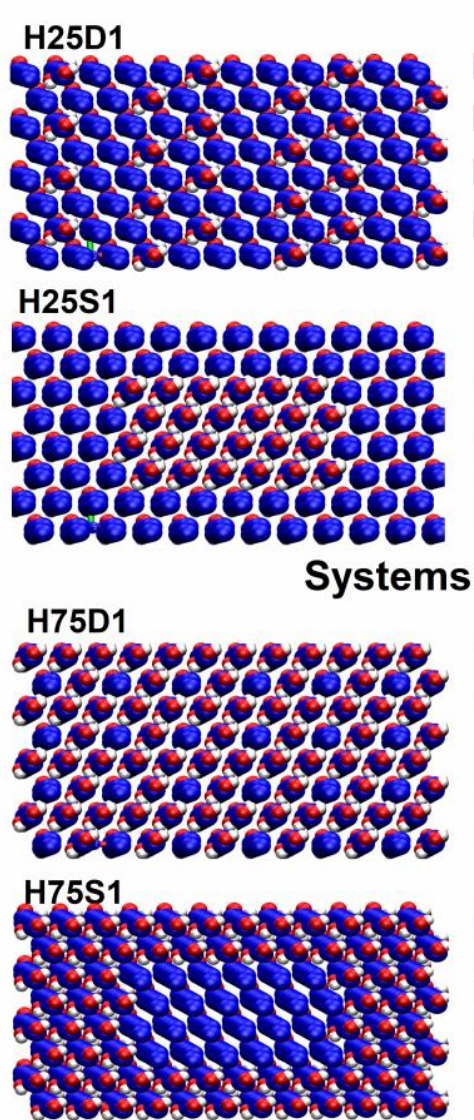

H25D2

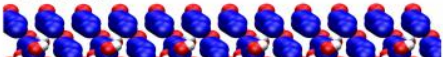

$12142 \%$

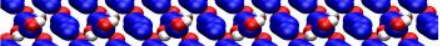

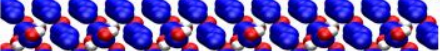

gor 35253

H25S2

H25S1

0100001

OOO OO

Dी 0 â?

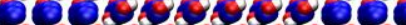

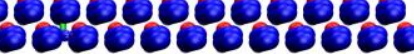

grgacergeg

$1921 \%$

$111 \times 121$

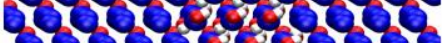

$\$ 2989189$

820016008

75:25

H75D2

trecoserocas

tertatatat

50 Sulas

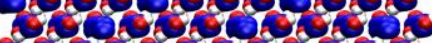

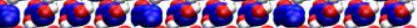

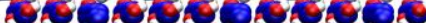

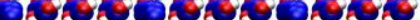

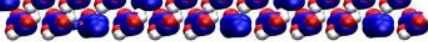

H75S2
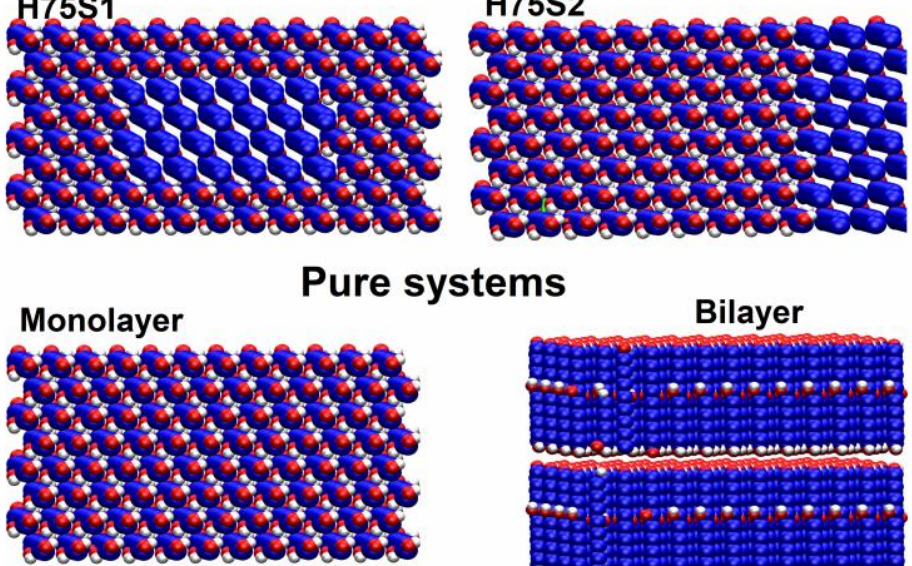

Bilayer

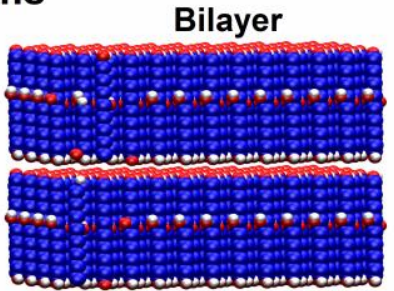

Figure 2. Initial configuration of all simulated systems. Systems with ALE:PAL compositions of 25:75, 75:25, and pure systems.

\section{RESULTS AND DISCUSSIONS}

\subsection{Pure ALE systems}

AFM images of pure self-assembled ALE (Figure 3A, right) show mostly isolated compact island $\approx$ $2.4 \mathrm{~nm}$ high (L2), as well as scattered detached tinny rounded agglomerates. Occasionally, bilayers

(L3) can also be observed. Higher resolution scanning (Figure 3A, left) reveals another flat and compact phase characterized by a lower height (L1). Additional AFM measurements (not shown) 
indicate that $L 1$, if compared to $L 2, L 3$ and mica background, are a low friction and low adhesion moieties. Previous work has demonstrated that L1 corresponds to a disordered and esterified arrangement of ALE molecules [26]. This study also justifies the predominance of vertically packed monolayer islands (L2) vs. bilayers (L3) due to the enhancement of the $2 \mathrm{D}$ vs. the $3 \mathrm{D}$ growing mechanism conditioned by the presence of the two secondary hydroxyls in the molecular skeleton.
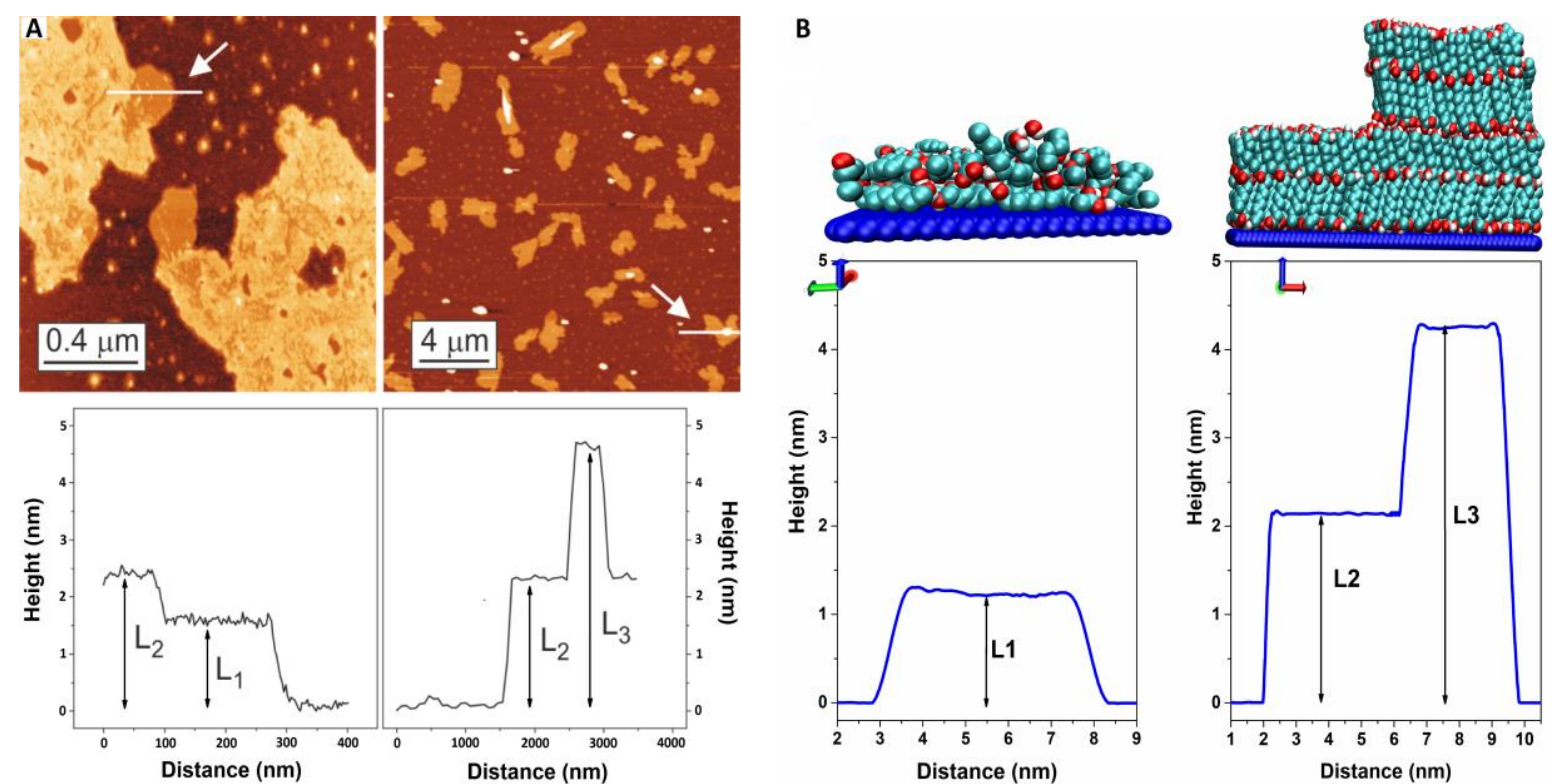

Figure 3. Experimental and theoretical height profile of self-assembled island. (A) Topographic AFM images of self-assembled island of pure ALE on mica. (B) Molecular dynamics simulations of the self-assembled island height profile of disorganized ALE monolayer (L1), self-assembled ALE monolayer (L2), and ALE bilayer (L3).

Simulations on these systems ( $\mathrm{L} 1, \mathrm{~L} 2$, and $\mathrm{L} 3$, Figure 3B) reveal two different ways for the $-\mathrm{COOH}$ and $-\mathrm{OH}$ groups to interact and to conduct to esterification reactions, namely route $1(\mathrm{R} 1)$ : when involving interactions between $-\mathrm{COOH}$ and primary $-\mathrm{OH}$ groups $(\mathrm{POH})$; and route 2 (R2): for $\mathrm{COOH}$ and secondary $-\mathrm{OH}$ groups $(\mathrm{SOH})$ interactions (Figure $\mathrm{S} 1$ ).

\section{ALE bilayers systems}

In the bilayers (denoted as L3 in the AFM images, Figure 3), the only way to favor an ER is through route $\mathrm{R} 1$, that is, when $-\mathrm{COOH}$ and $\mathrm{POH}$ groups interact (Figure S2). Figure 4 shows the radial distribution functions (RDF) for these groups. The plot for carbon and oxygen distances ( $(\mathrm{g}(\mathrm{c}-\mathrm{o})$ ) presents two peaks at 3.2 and $3.7 \AA$, and three peaks at $1.8,3.0$, and $3.8 \AA$ for hydrogen and oxygen distances $\left(\mathrm{g}_{(\mathrm{H}-\mathrm{O})}\right)$. We analyze these distances (named as $\delta 1$ and $\delta 2$ ) to understand which of 
those peaks are related to an ER. Taking advantage of the fact that $\delta 1$ and $\delta 2$ would be correlated if an ER occurs, combined distribution functions (CDF) are used to poll zones where ER can happen. We use the TRAVIS [27] code to perform all analyses, and they are illustrated in Figure 5. There are three predominant zones: zone $1(1.6<\delta 1<2.5 \AA$ and $3.5<\delta 2<4.0 \AA ̊)$; zone $2(2.5<\delta 1<3.3 \AA$ and $3.0<\delta 2<3.8)$ and, zone $3(3.5<\delta 1<4.5 \AA$ and $3.4<\delta 2<4.1 \AA$ ). It is also clear, when comparing the relative intensity of all zones, that zone 1 is rarely visited and the system remains the longest in zones 2 and 3.

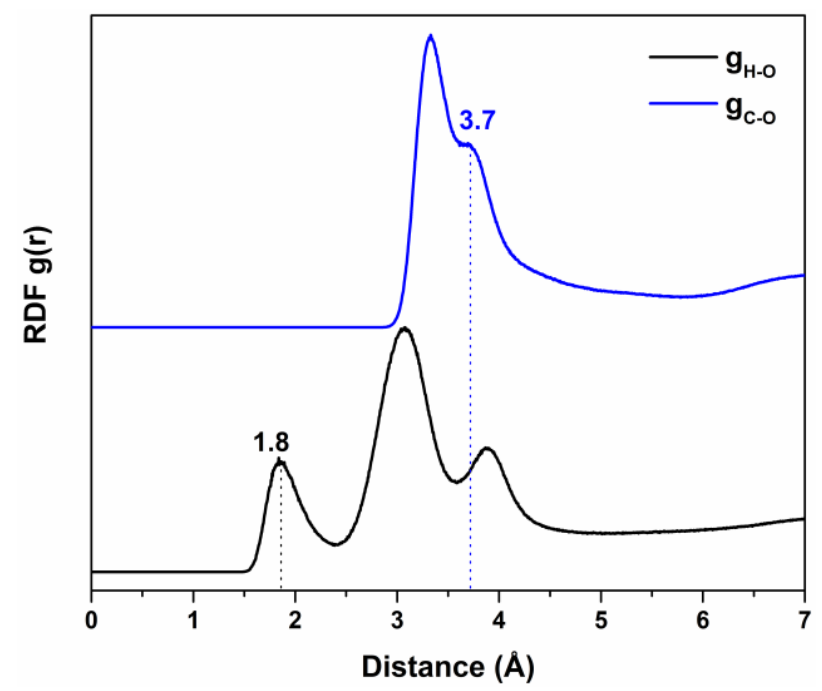

Figure 4. Radial distribution function (RDF). Analysis of the R1 route for an ER. L3-ALE bilayer system.

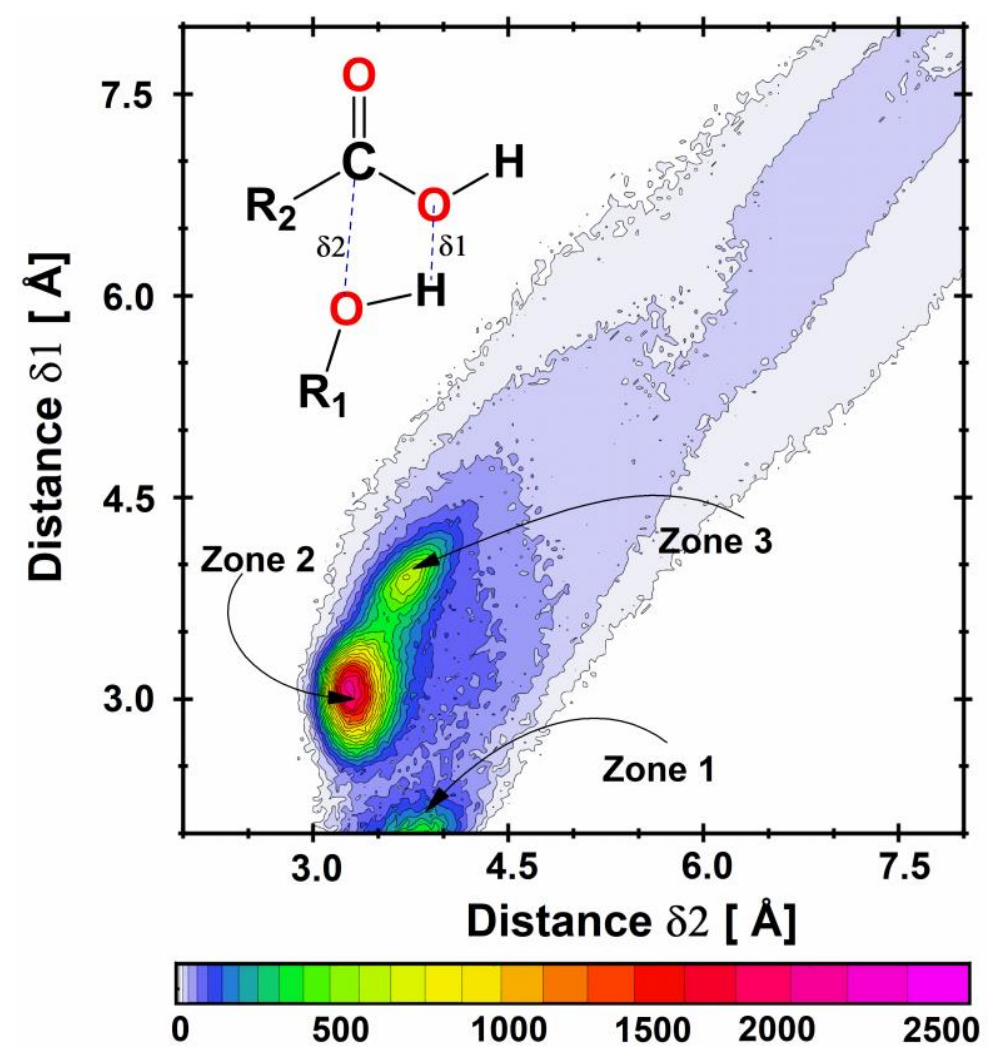


Figure 5. Combined Distribution Functions (CDF) for bilayers L3 with two channels: $\delta 1$ and $\delta 2$ distances.

Analyzing the configurational arrangements existing in those three zones, they can be schematically summarized as represented in Figure 6 . In zone 1 , there is a configuration with $\delta 1=$ $3.7 \AA$ and $\delta 2=1.8 \AA$, where $-\mathrm{COOH}$ and $\mathrm{POH}$ groups get an adequate configuration to favor an $\mathrm{ER}$. For this reason, the presence of these peaks is only monitored in the next systems. It is likely that this configuration is stabilized by $\mathrm{H}$-bond interactions ( $\mathrm{H}$-bond 1 ) formed between the $\mathrm{POH}$ group and the protonated oxygen of the $-\mathrm{COOH}$ group.

In zone 2, we find two different configurations that are also possibly stabilized by $\mathrm{H}$-bond interactions. In this zone, the $\mathrm{POH}$ group interacts with the unprocessed oxygen of $-\mathrm{COOH}(\mathrm{H}$-bond 2). This type of $\mathrm{H}$-bond prevents an ER from occurring since it would not be possible to get a fitting initial configuration.

Similarly, the main configuration in zone 3 may also be stabilized by $\mathrm{H}$-bond interactions. The $-\mathrm{OH}$ of the $-\mathrm{COOH}$ group interacts with the oxygen of the $\mathrm{POH}(\mathrm{H}$-bond 3$)$. This configuration also prevents an ER from occurring.

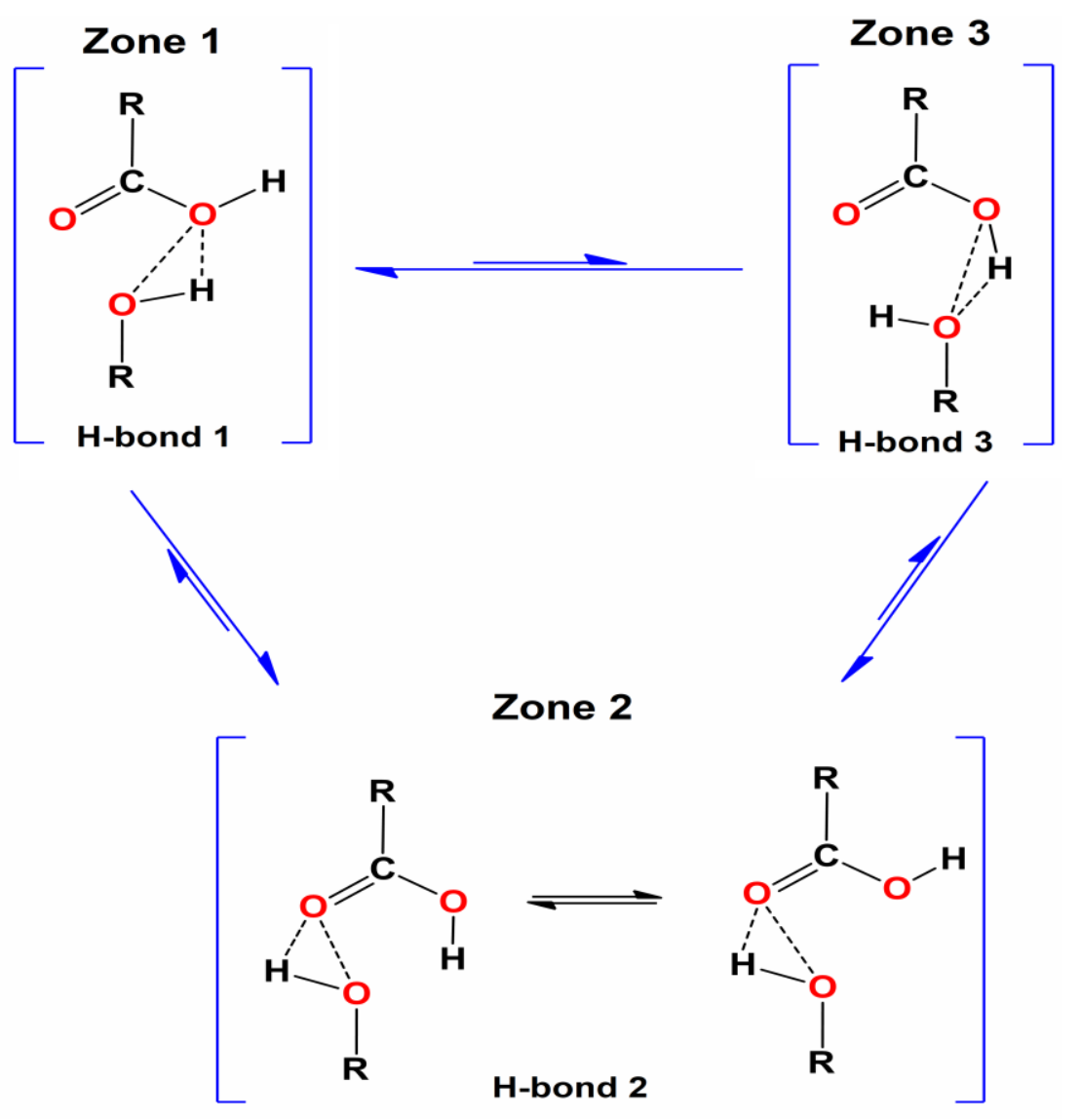


Figure 6. Schematic arrangements found when the $-\mathrm{COOH}$ and $-\mathrm{OH}$ groups interact with each other in ALE self-assembled bilayers (L3 structures in Figure 3).

All these results show that to favor an ER it is necessary to meet two requirements: the hydrogen of the $-\mathrm{COOH}$ group has to be oriented upwards, and also, $\mathrm{H}$-bond interactions of type 1 (H-bond 1) must occur.

The presence of the three types of $\mathrm{H}$-bonds ( $\mathrm{H}$-bond $1, \mathrm{H}$-bond 2 , and $\mathrm{H}$-bond 3 ) was confirmed by Combined Distribution Functions (CDF). Specifically, radial and angular distribution functions (RDF and ADF) were used to monitor the presence of $\mathrm{H}$-bond $\left(\mathrm{r}_{0-0}\right.$ and $\left.\alpha\right)$, and the results are presented in Figure 7.
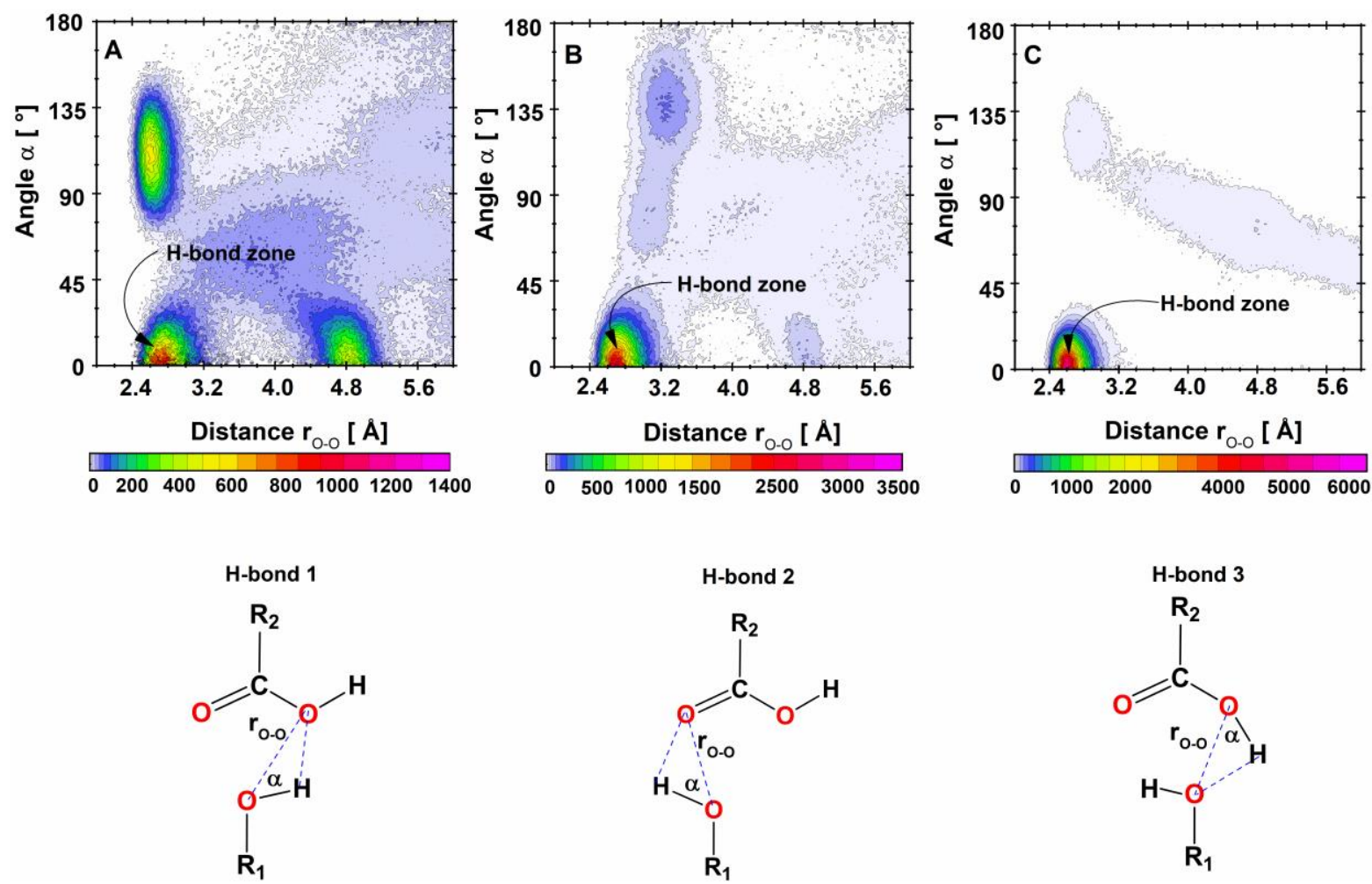

Figure 7. Combined Distribution Functions (CDF) with channels ro-o distance and $\alpha$ angle. (A) For Hbond 1 (C) For H-bond 2 and (C) For H-bond 3. L3-ALE bilayer system.

Analyzing all possible $\mathrm{H}$-bonds, it is clear that, effectively, all zones are stabilized by $\mathrm{H}$-bond interactions ( $r_{\mathrm{o}-\mathrm{o}} \leq 3.0 \AA$ and $\alpha \leq 20^{\circ}$ ). Also, it was confirmed that the local minimum in zone 1 is the least stable by having a lower number of $\mathrm{H}$-bonds $(\mathrm{H}$-bond number ratios: $\mathrm{H}$-bond2/H-bond1 2.5 and $\mathrm{H}$-bond3/H-bond1 $~ 4.3$ ). This result confirms that the local minimum that favors an ER (zone 1 ) is the least visited and is not the most stable region, making clear that an ER could be poorly favored. 


\section{ALE monolayers systems}

MD simulations of ALE monolayers starting from initial configurations where molecules were vertically aligned or disorganized allowed us to assign the L1 and L2 structures observed in the AFM images from Figure 3. Thus, L2 structures with higher height correspond to ALE selfassembled monolayers. Analyzing the density distribution along the Z-direction of the $-\mathrm{COOH}, \mathrm{POH}$ and $\mathrm{SOH}$ groups, it is observed that the way they distribute prevents any possibility of favoring an ER (Figures 3B and S3). Therefore, it is expected that an ER does not occur in monolayers of vertically packed ALE molecules as deduced from AFM results [26].

On the other hand, the lower height structures (L1) can be explained from simulations of disorganized monolayers. In these systems (Figures 3B and S4) the RDF results for both ER routes show similar behaviors (Figure 8). Thus, $\mathrm{g}_{(\mathrm{C}-\mathrm{O})}$ has two peaks at 3.2 and $3.7 \AA$ and $\mathrm{g}_{(\mathrm{H}-\mathrm{O})}$ plot shows three peaks at $1.8,3.0$, and $3.8 \AA$ (Figure $8 \mathrm{~A}$ and $8 \mathrm{~B}$ ). All these peaks form three local minima that are most visited throughout the simulation trajectory (Figure 4). Zone 1 (about $d(C-O)=3.7 \AA$ and $d(H-O)=1.8 \AA)$ corresponds to the region that favors an ER, where, the presence of the peak at $d(C$ O)=3.7 $\AA$ ensures a required approximation distance favorable to a nucleophilic attack. Also, the peak at $\mathrm{d}(\mathrm{O}-\mathrm{H})=1.8 \AA$ indicates a propitious distance for the formation of the water molecule.
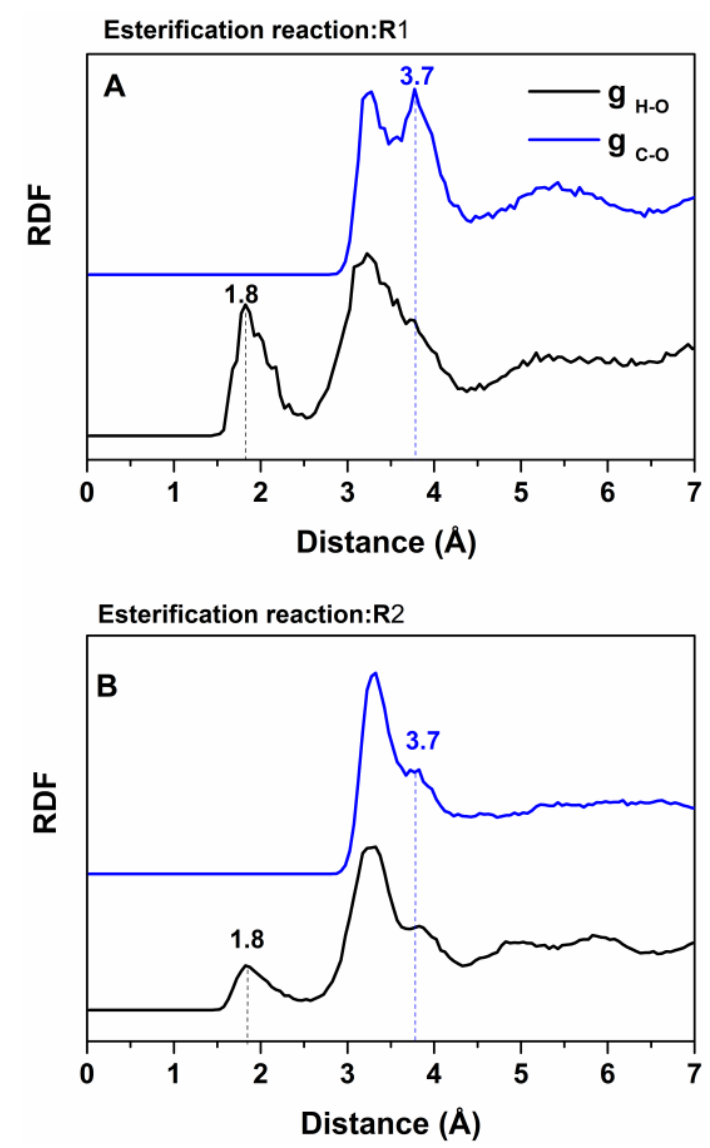

Figure 8. Radial distribution functions (RDF) for interactions in the ALE monolayer L1 system between: (A) $\mathrm{COOH}$ and $\mathrm{POH}$ groups (R1 route), and, (B) $-\mathrm{COOH}$ and $\mathrm{SOH}$ groups ( $\mathrm{R} 2$ route). 


\subsection{Mixed systems}

\section{5:25 (ALE:PAL) composition}

In a previous study [28], we analyzed the self-assembling process of mixtures of 75:25 composition, and we showed that the ALE molecules are still well organized when compared to the pure ALE monolayers. That work shows that the density profile along the Z-direction, $\rho(z)$ of the active groups, shows a slight dislocation of the molecules that could favor interaction between the $-\mathrm{COOH}$ and $\mathrm{SOH}$ groups, both for segregated and dispersed systems. Also, $\rho(\mathrm{z})$ shows that there is not a convenient approach between the other reacting groups, and therefore, the interactions between $-\mathrm{COOH}$ and $\mathrm{POH}$ groups are hampered. Under these conditions, an ER could occur exclusively between the $-\mathrm{COOH}$ and $\mathrm{SOH}$ groups. These suggestions were also analyzed using the radial distribution functions (RDF), which are depicted in Figure 9 for the H75D1 system. The other systems have the same behavior, and they are shown in the supplementary material (Figure S5).

It can be seen that all studied systems (dispersed and segregated) for R2 route present characteristic peaks for $\mathrm{g}_{(\mathrm{C}-\mathrm{O})}$ and $\mathrm{g}_{(\mathrm{O}-\mathrm{H})}$ at 3.7 and $1.8 \AA$, respectively (Figure 9B), whereas, the absence of these peaks for R1 route (Figure 9A) indicates that both groups are not arranged conveniently to favor an ER. These results imply that under high ALE concentrations, ER can only occur through the $\mathrm{R} 2$ route.

It was also observed that the $-\mathrm{COOH}$ groups of the ALE and PAL molecules exhibit different behaviors, indicating a different role in the ER through the R2 route. They were analyzed by defining the angle $\beta$ formed between the $Z$-direction and the normal vector to the plane formed by the $\mathrm{C}-\mathrm{O}-\mathrm{O}$ atoms of the $-\mathrm{COOH}$ group. The $\beta$ distributions are shown in Figure S6. It is observed that, even though the molecules remained confined in a compacted and orderly configuration, the $-\mathrm{COOH}$ groups, both in ALE and PAL molecules, can reorient in any possible orientation, mainly PAL-COOH groups.

The ALE- $\mathrm{COOH}$ groups have different orientations when compared between segregated and dispersed systems. The angles at $30^{\circ}$ and $140^{\circ}$ are more pronounced in the most stable (segregated) systems and slightly less in the dispersed ones. On the other hand, PAL-COOH groups are randomly distributed in all systems (Figure S6). This fact suggests that PAL-COOH groups could be interacting to a lesser extent than ALE- $\mathrm{COOH}$ groups with other functional groups such as $\mathrm{SOH}$. In ALE rich systems, the lower tendency of PAL-COOH to interact with SOHs of ALE molecules is compatible with the ideal behavior observed by AFM, i.e., a low degree of mixing and the occurrence of segregation between ALE and PAL phases [28]. 


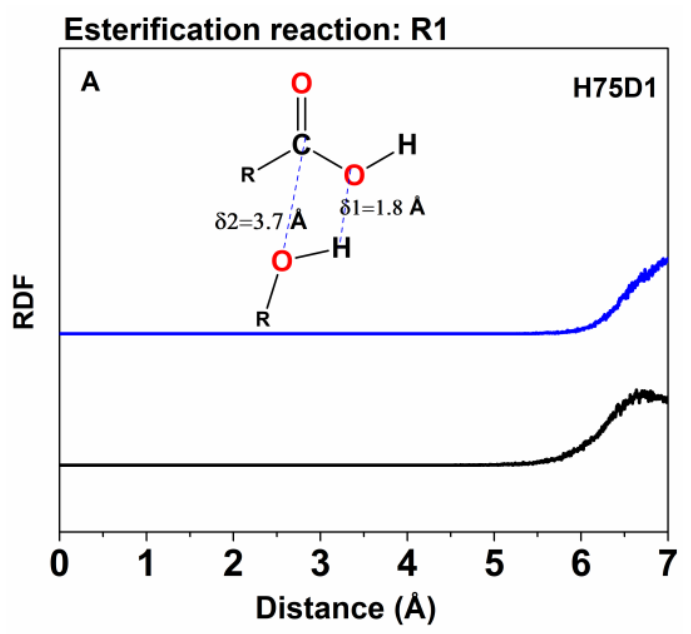

Esterification reaction: $\mathbf{R} 2$

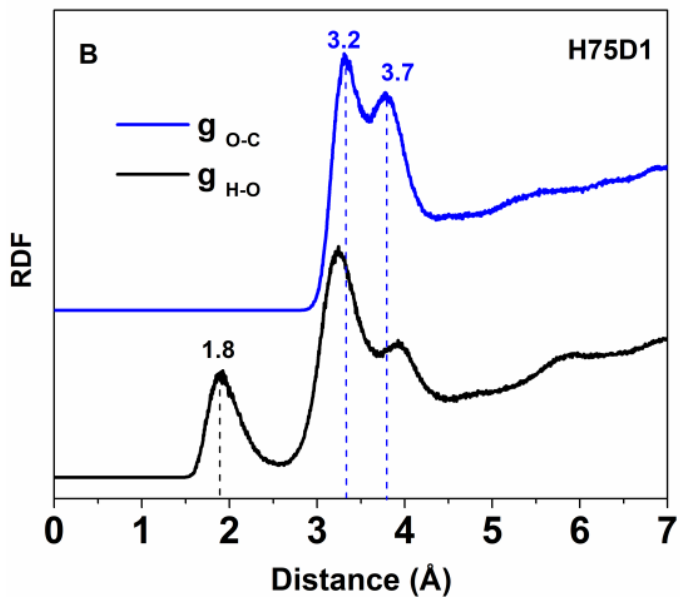

Figure 9. Radial distribution functions (RDF) for interactions in the H75D1 system between: (A) $\mathrm{COOH}$ and $\mathrm{POH}$ groups ( $\mathrm{R} 1$ route), and, (B) $-\mathrm{COOH}$ and $\mathrm{SOH}$ groups (R2 route).

\section{5:75 (ALE:PAL) composition}

In these systems, due to a large number of PAL molecules, the self-assembling of ALE molecules is almost entirely lost. The density profile $\rho(z)$ analysis shows that there is a dislocation of ALE molecules along the Z-direction, facilitating interactions between all groups, that is, $(-\mathrm{COOH})---$ $(\mathrm{POH})$ and (-COOH)---(SOH) (Figure S7). Again, RDF was used to check whether these interactions could effectively favor possible ER. The corresponding plots for the H25D2 system are reported in Figure 10, whereas the other systems have the same behavior and are shown in the supplementary material (Figure S8).

As expected, due to the increased disorder in the systems, an ER via R2 route is even more favored, as indicated from the intensity of the peak at $3.7 \AA$ for $\mathrm{g}_{(\mathrm{C}-\mathrm{O})}$ (Figure 10B). On analyzing the R1 
route, unlike the previous case for $75: 25$ systems, it is now observed that ER also occurs via $R 1$ route (Figure 10A). This is evidenced by the peaks in $g_{(\mathrm{C}-\mathrm{O})}$ and $\mathrm{g}_{(\mathrm{O}-\mathrm{H})}$ at 3.7 and $1.8 \AA$, respectively. Also, the higher height of the first peak and lesser overlapping with the close peak at $3.3 \AA$, suggests that this route (R1) would be slightly more favored compared to R2 route, only in disordered systems. The potentiation of both R1 and R2 mechanisms in PAL rich mixtures would support the reported non-ideal behavior and the enhanced development of the mixed configuration in 25:75 (ALE:PAL) compositions, as revealed by AFM data. The nature of such a mixed phase (phase II) would be constituted by both pure assembled PAL and PAL-ALE interacting molecules [28].
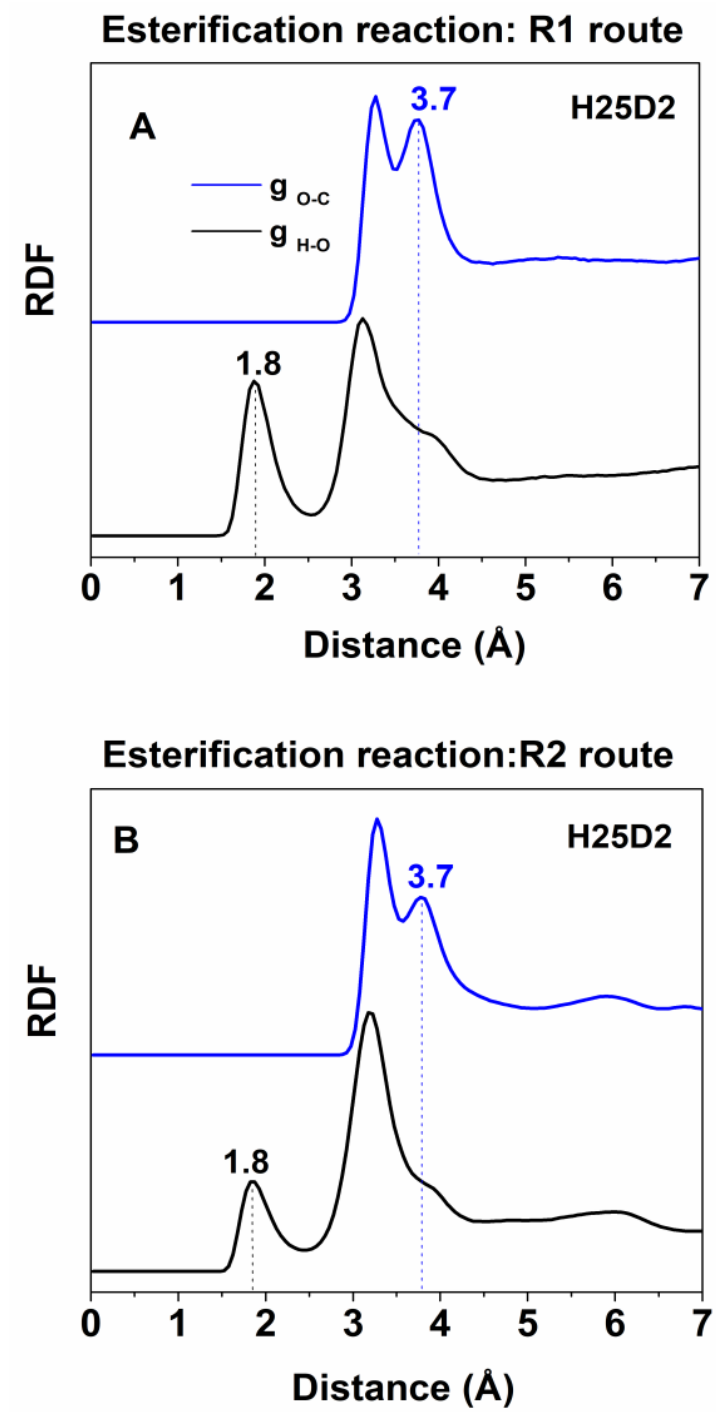

Figure 10. Radial distribution functions (RDF) for interactions in the H25D2 system between: (A) $\mathrm{COOH}$ and $\mathrm{POH}$ groups ( $\mathrm{R} 1$ route), and, (B) $-\mathrm{COOH}$ and $\mathrm{SOH}$ groups ( $\mathrm{R} 2$ route). 


\section{CONCLUSIONS}

Despite the limitations of classical molecular dynamics simulations to study chemical reactions, we present valuable parameters allowing us to infer possible routes for ER occurring when pure ALE and ALE/PAL mixtures are deposited on a support.

Systems formed from some cutin monomers have the ability to form self-assembled structures. The loss of ability for self-assembling of these systems leads to favoring esterification reactions, and as the disorder increases the number of possible esterification routes increases.

For example, the 75:25 system keeps significantly a well-organized structure and the ER is only favored through $\mathrm{R} 2$ route (- $\mathrm{COOH}$ and $\mathrm{SOH}$ interactions). For the 25:75 ALE system, having lost all its self-assembly ability, it is observed that both R1 and R2 routes are favored. In pure ALE systems, it becomes evident that self-assembled monolayers do not have the ability to form ER. However, when monolayers are disorganized, the R1 and R2 routes are favored. Finally, for bilayer pure ALE systems, where the system is well organized only the R1 route is favored due to interactions between $-\mathrm{COOH}$ from the upper layer with the $\mathrm{POH}$ in the lower layer.

\section{DATA AVAILABILITY}

The data that supports the findings of this study are available within the article [and its supplementary material].

\section{AUTHOR'S CONTRIBUTIONS}

All authors contributed equally to this work.

\section{CONFLICTS OF INTEREST}

There are no conflicts to declare.

\section{ACKNOWLEDGEMENTS}

This work was funded in part by Fundação de Amparo à Pesquisa do Estado de São Paulo - FAPESP (2013/07296-2; 2016/23891-6) and National Council for the Improvement of Higher Education (CAPES). This work used computational resources of the "Centro Nacional de Processamento de Alto Desempenho em São Paulo" (CENAPAD-SP), "Centro de Computação John David Rogers" (CCJDR-UNICAMP), and the CENAPAD-RJ (SDumont). 


\section{REFERENCES}

1. Kolattukudy, P. E., Biopolyester Membranes of Plants: Cutin and Suberin. Science 1980, 208 (4447), 990-1000.

2. Heredia-Guerrero, J. A.; Heredia, A.; Domínguez, E.; Cingolani, R.; Bayer, I. S.; Athanassiou, A.; Benítez, J. J., Cutin from agro-waste as a raw material for the production of bioplastics. Journal of Experimental Botany 2017, 68 (19), 5401-5410.

3. Gandini, A.; Pascoal Neto, C.; Silvestre, A. J. D., Suberin: A promising renewable resource for novel macromolecular materials. Progress in Polymer Science 2006, 31 (10), 878-892.

4. Heredia-Guerrero, J. A.; San-Miguel, M. A.; Luna, M.; Domínguez, E.; Heredia, A.; Benítez, J. J., Structure and support induced structure disruption of soft nanoparticles obtained from hydroxylated fatty acids. Soft Matter 2011, 7 (9), 4357-4363.

5. Domínguez, E.; Heredia-Guerrero, J. A.; Benítez, J. J.; Heredia, A., Self-assembly of supramolecular lipidnanoparticles in the formation of plant biopolyester cutin. Molecular BioSystems 2010, 6 (6), 948-950.

6. Heredia-Guerrero, J. A.; Domínguez, E.; Luna, M.; Benítez, J. J.; Heredia, A., Structural characterization of polyhydroxy fatty acid nanoparticles related to plant lipid biopolyesters. Chemistry and Physics of Lipids 2010, 163 (3), 329-333.

7. Kwiatkowska, M.; Wojtczak, A.; Popłońska, K.; Polit, J.; Stępiński, D.; Dominguez, E.; Heredia, A., Cutinsomes and lipotubuloids appear to participate in cuticle formation in Ornithogalum umbellatum ovary epidermis: EM-immunogold research. Protoplasma 2014, 251.

8. Correia, V. G.; Bento, A.; Pais, J.; Rodrigues, R.; Haliński, Ł. P.; Frydrych, M.; Greenhalgh, A.; Stepnowski, P.; Vollrath, F.; King, A. W. T.; Silva Pereira, C., The molecular structure and multifunctionality of the cryptic plant polymer suberin. Materials Today Bio 2020, 5, 100039.

9. Heredia-Guerrero, J. A.; Domínguez, E; San-Miguel, M. A.; Benítez, J. J.; Heredia, A. Self-assembly and polymerization of natural occurring fatty acids. In Advances in Materials Science Research vol. 6, chapter 5. M. C. Wythers, ed. Nova Science Publishers (2011).

10. Heredia-Guerrero, J. A.; Caputo, G.; Guzman-Puyol, S.; Tedeschi, G.; Heredia, A.; Ceseracciu, L.; Benitez, J. J.; Athanassiou, A., Sustainable polycondensation of multifunctional fatty acids from tomato pomace agro-waste catalyzed by tin (II) 2-ethylhexanoate. Materials Today Sustainability 2019, 3-4, 100004. 
11. Manrich, A.; Moreira, F. K. V.; Otoni, C. G.; Lorevice, M. V.; Martins, M. A.; Mattoso, L. H. C., Hydrophobic edible films made up of tomato cutin and pectin. Carbohydrate Polymers 2017, 164, 83-91.

12. Montanari, A.; Bolzoni, L.; Cigognini, I. M.; Ciruelos, A.; Gómez Cardoso, M.; de la Torre, R. In Tomato bio-based lacquer for sustainable metal packaging, International Society for Horticultural Science (ISHS), Leuven, Belgium: 2017; pp 159-166.

13. Tedeschi, G.; Benitez, J. J.; Ceseracciu, L.; Dastmalchi, K.; Itin, B.; Stark, R. E.; Heredia, A.; Athanassiou, A.; Heredia-Guerrero, J. A., Sustainable Fabrication of Plant Cuticle-Like Packaging Films from Tomato Pomace Agro-Waste, Beeswax, and Alginate. ACS Sustainable Chemistry \& Engineering 2018, 6 (11), 14955-14966.

14. Heredia-Guerrero, J. A.; San-Miguel, M. A.; Sansom, M. S. P.; Heredia, A.; Benítez, J. J., Chemical Reactions in 2D: Self-Assembly and Self-Esterification of 9(10),16-Dihydroxypalmitic Acid on Mica Surface. Langmuir 2009, 25 (12), 6869-6874.

15. Glowacki, D. R.; Paci, E.; Shalashilin, D. V., Boxed Molecular Dynamics: A Simple and General Technique for Accelerating Rare Event Kinetics and Mapping Free Energy in Large Molecular Systems. The Journal of Physical Chemistry B 2009, 113 (52), 16603-16611.

16. Smith, W.; Forester, T. R., DL_POLY_2.0: A general-purpose parallel molecular dynamics simulation package. Journal of Molecular Graphics 1996, 14 (3), 136-141.

17. Nauchitel, V. V., Energy distribution function for the NVT canonical ensemble. Molecular Physics 1981, 42 (5), 1259-1265.

18. Evans, D. J.; Holian, B. L., The Nose-Hoover thermostat. The Journal of Chemical Physics 1985, $83(8), 4069-4074$.

19. Pastor, R. W.; MacKerell, A. D., Development of the CHARMM Force Field for Lipids. The Journal of Physical Chemistry Letters 2011, 2 (13), 1526-1532.

20. San-Miguel, M. A.; Rodger, P. M., Templates for wax deposition? Physical Chemistry Chemical Physics 2010, 12 (15), 3887-3894.

21. San-Miguel, M. A.; Rodger, P. M., The effect of corrosion inhibitor films on deposition of wax to metal oxide surfaces. Journal of Molecular Structure: THEOCHEM 2000, 506 (1), 263-272.

22. San-Miguel, M. A.; Rodger, P. M., Simulation of Deposition of Wax to Iron Oxide Surfaces. Molecular Simulation 2001, 26 (3), 193-216.

23. Begić, S.; Jónsson, E.; Chen, F.; Forsyth, M., Molecular dynamics simulations of pyrrolidinium and imidazolium ionic liquids at graphene interfaces. Physical Chemistry Chemical Physics 2017, 19 (44), 30010-30020. 
24. Yokota, Y.; Miyamoto, H.; Imanishi, A.; Inagaki, K.; Morikawa, Y.; Fukui, K.-i., Structural and dynamic properties of 1-butyl-3-methylimidazolium bis(trifluoromethanesulfonyl)imide/mica and graphite interfaces revealed by molecular dynamics simulation. Physical Chemistry Chemical Physics 2018, 20 (9), 6668-6676.

25. Lee, S.; Lyulin, A. V.; Frank, C. W.; Yoon, D. Y., Interface characteristics of polystyrene melts in free-standing thin films and on graphite surface from molecular dynamics simulations. Polymer 2017, 116, 540-548.

26. Heredia-Guerrero, J. A.; San-Miguel, M. A.; Sansom, M. S. P.; Heredia, A.; Benítez, J. J., Aleuritic (9,10,16-trihydroxypalmitic) acid self-assembly on mica. Physical Chemistry Chemical Physics 2010, 12 (35), 10423-10428.

27. Brehm, M.; Kirchner, B., TRAVIS - A Free Analyzer and Visualizer for Monte Carlo and Molecular Dynamics Trajectories. Journal of Chemical Information and Modeling 2011, 51 (8), 2007-2023.

28. Bueno, O. V. M.; Benítez, J. J.; San-Miguel, M. A., Understanding segregation processes in SAMs formed by mixtures of hydroxylated and non-hydroxylated fatty acids. RSC Advances 2019, 9 (67), 39252-39263. 


\section{Elucidating esterification reaction during deposition of cutin monomers from classical molecular dynamics simulations}

Otto V.M. Bueno, J. J. Benítez and Miguel A. San-Miguel

a Department of Physical Chemistry, Institute of Chemistry, University of Campinas UNICAMP, P.O. Box 6154, 13083-970 Campinas, SP, Brazil. E-mail: smiguel@unicamp.br

b Instituto de Ciencias de Materiales de Sevilla, Centro Mixto CSIC-Universidad de Sevilla, Avda, Americo Vespuccio, 49 (41092)-Sevilla, Spain

ELECTRONIC SUPPLEMENTARY INFORMATION 


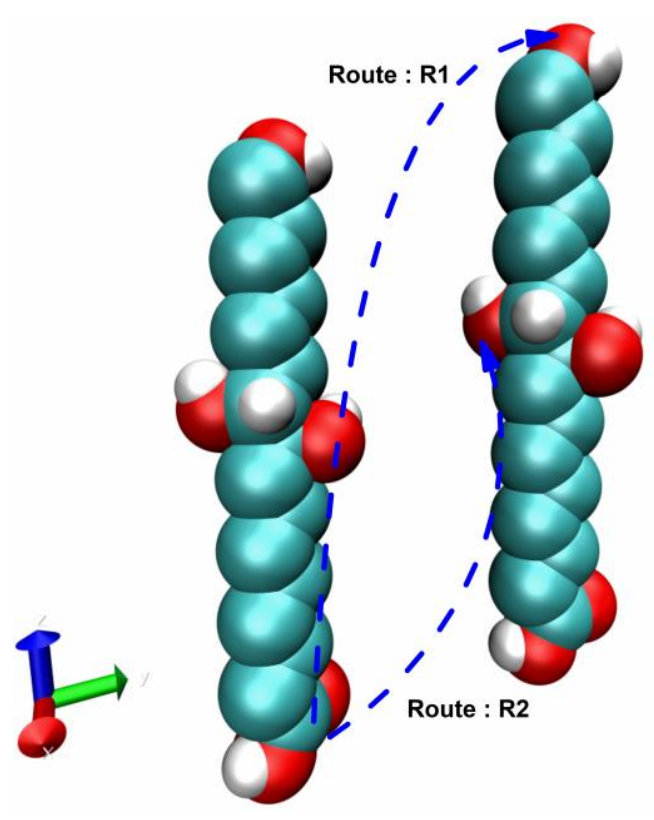

Figure S1. Possible ER routes between $-\mathrm{COOH}$ and $\mathrm{POH}$ groups (R1), and, $-\mathrm{COOH}$ and SOH groups (R2). 


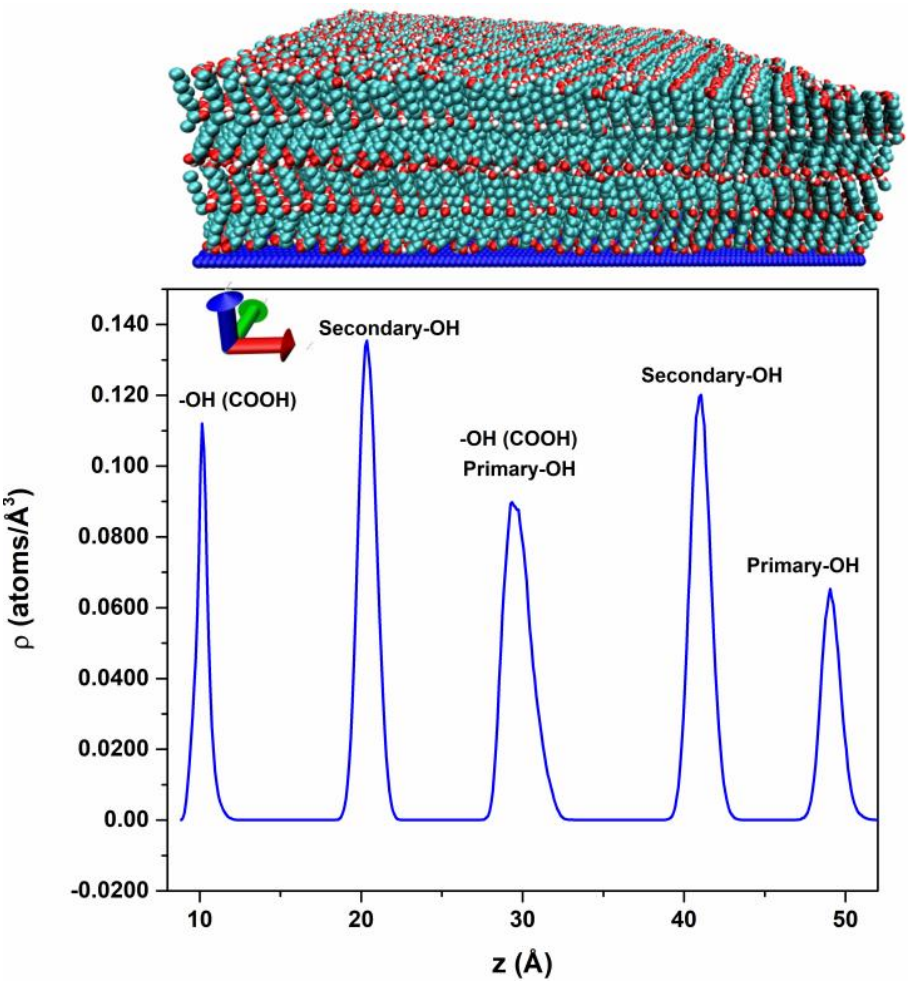

Figure S2. Density profile along the Z-axis of the active groups $-\mathrm{COOH}$ and primary and secondary -OH groups, for the pure ALE bilayer L3 system. 


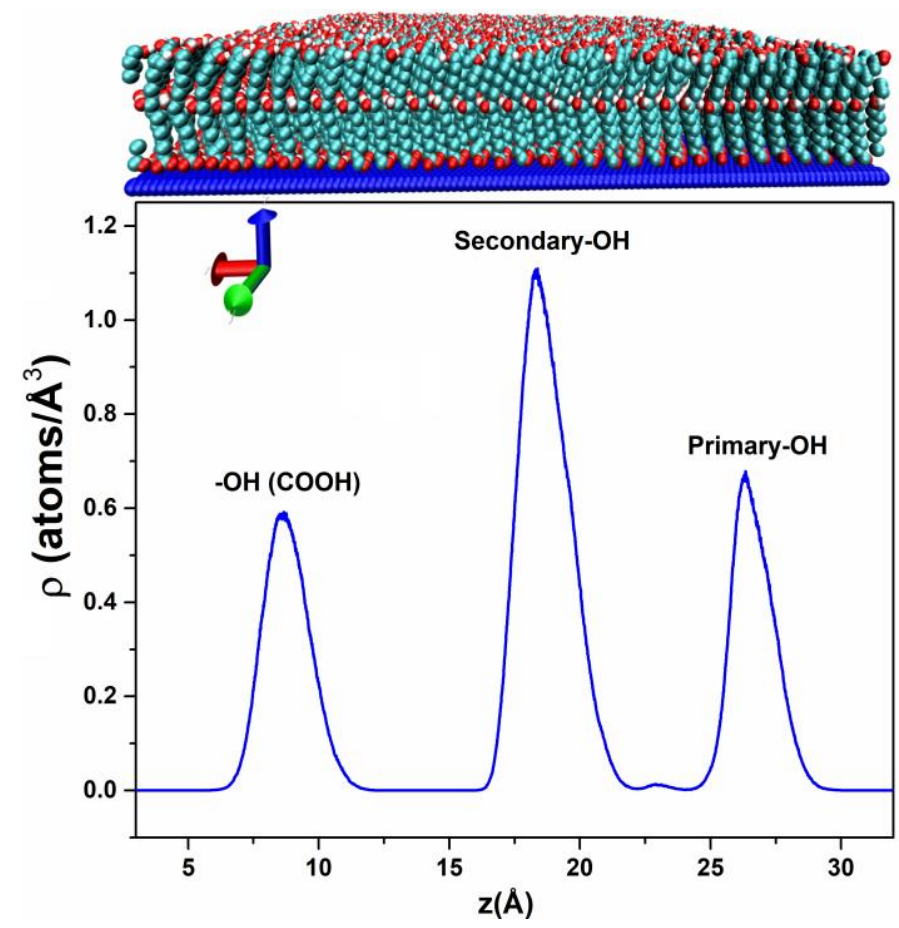

Figure S3. Density profile along the Z-axis of the active groups $-\mathrm{COOH}$ and primary and secondary- $\mathrm{OH}$, for the pure ALE monolayer L2 system. 


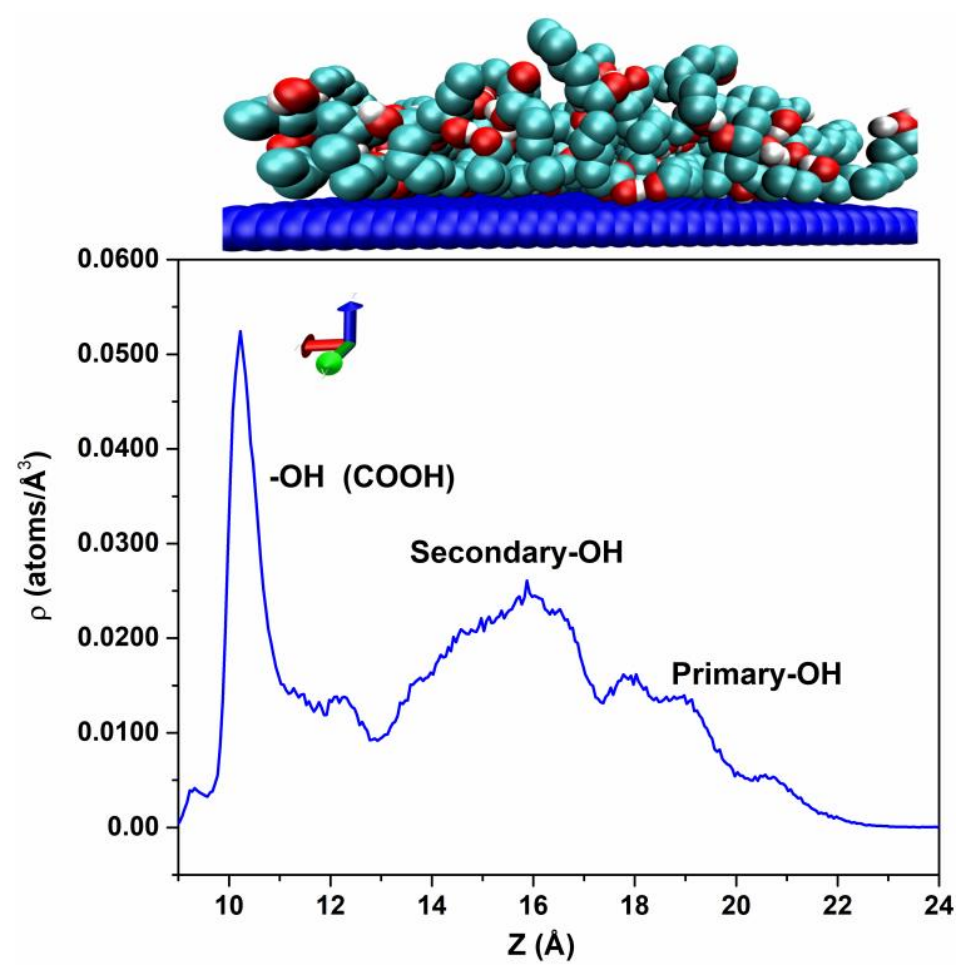

Figure S4. Density profile along the Z-axis of the active groups $-\mathrm{COOH}$ and primary and secondary- $\mathrm{OH}$, for the pure ALE monolayer L1 system. 


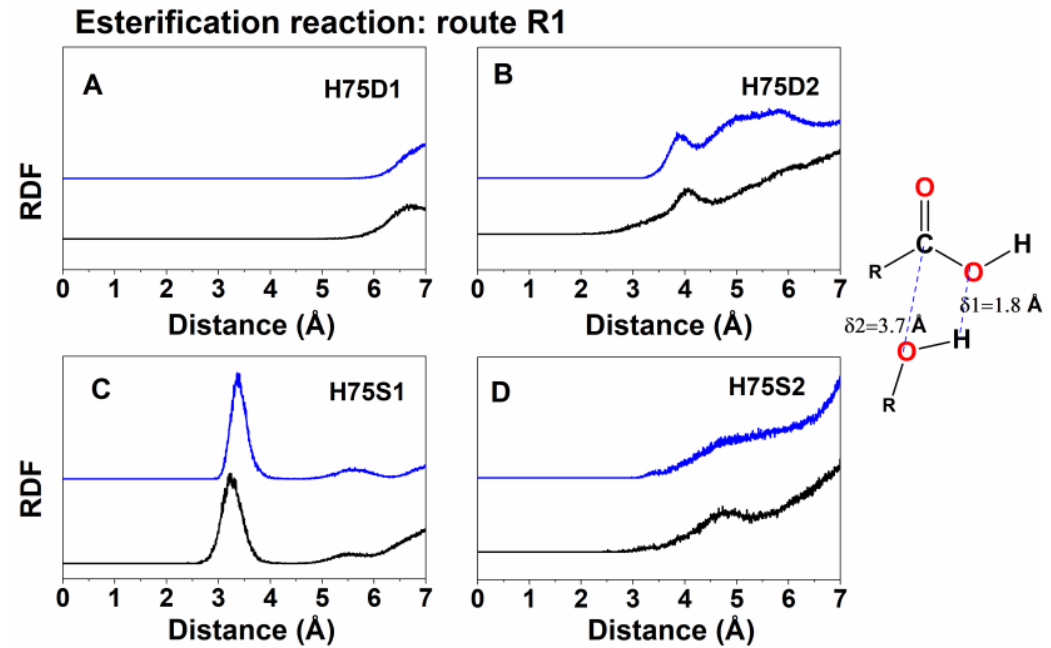

Esterification reaction: route $\mathbf{R} 2$
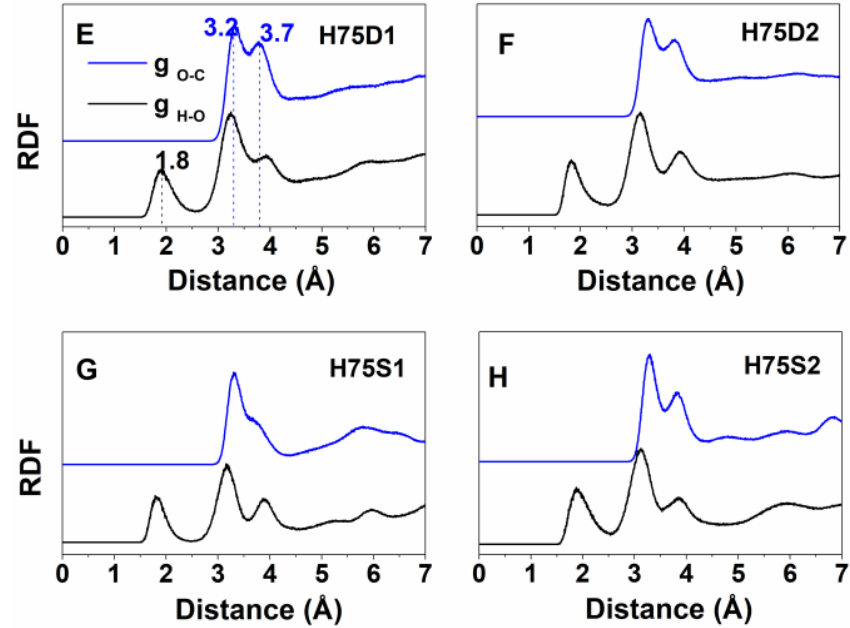

Figure S5. Radial distribution function (RDF) of the $\mathrm{COOH}$ and $\mathrm{OH} 1$ groups (route 1) and of the $\mathrm{COOH}$ and $\mathrm{OH} 2$ groups (route 2). (A), (B), (C) and (D) possible ER on route R2. (E), (F), (G) and $(\mathrm{H})$ possible ER on route $\mathrm{R} 1$. 

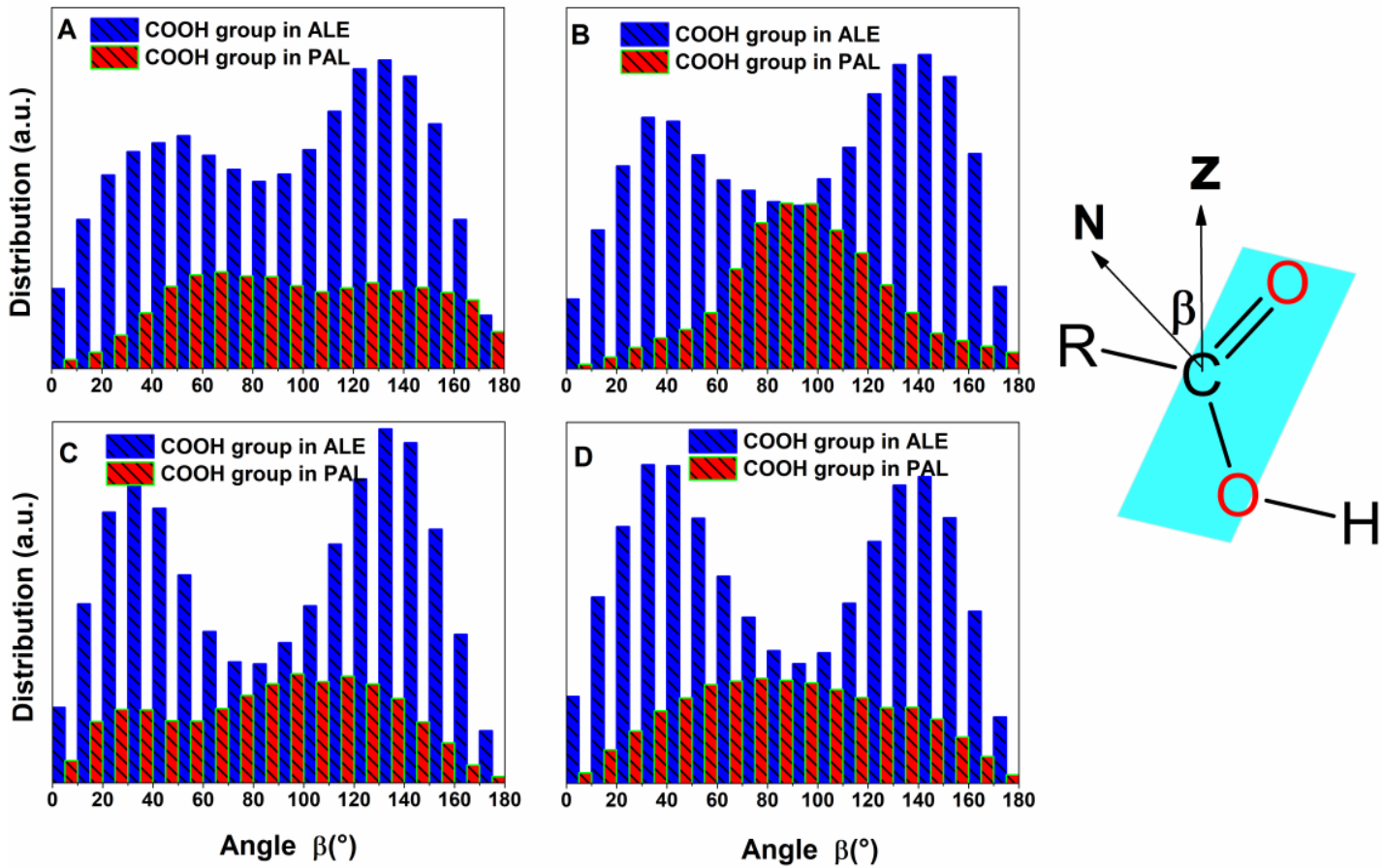

Figure S6. Angle distribution $(\beta)$. The distribution in red represents the $\mathrm{COOH}$ groups of PAL and the blue of ALE . (A) and (B) dispersed systems, (C) and (D) segregated systems. 


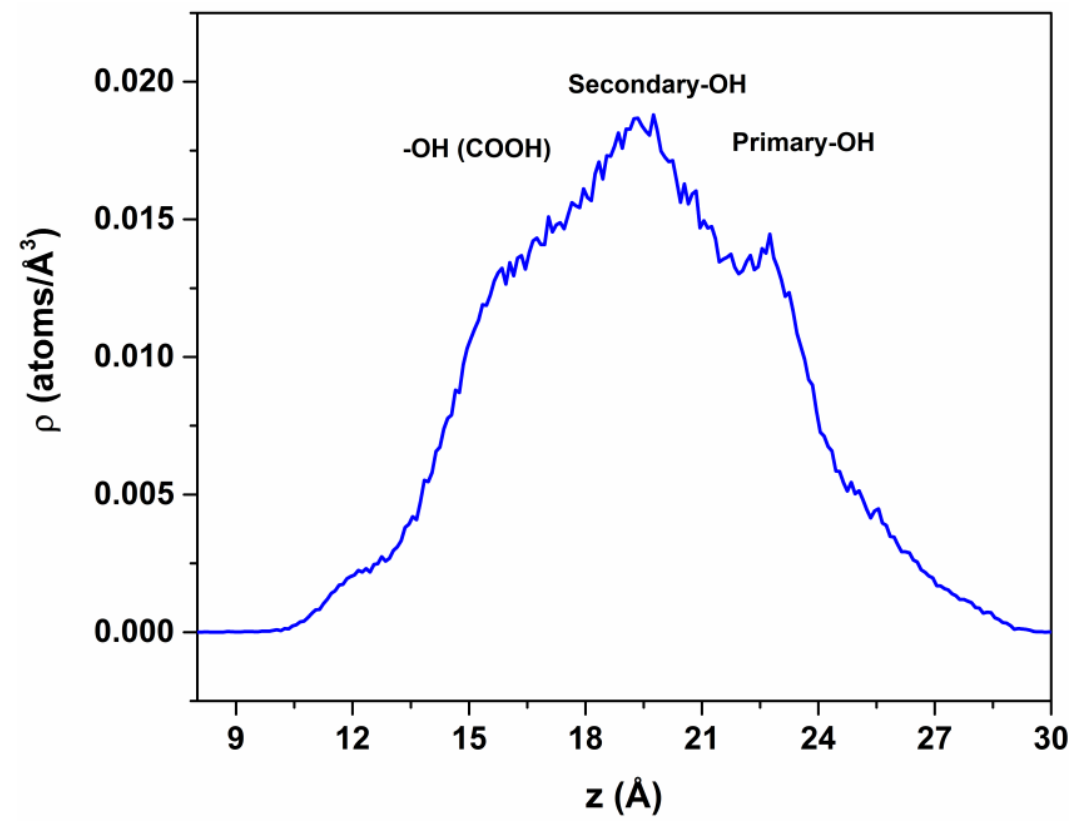

Figure S7. Density profile along the Z-axis of the active groups $-\mathrm{COOH}$ and primary and secondary- $\mathrm{OH}$, for the composition 25:75 system. 

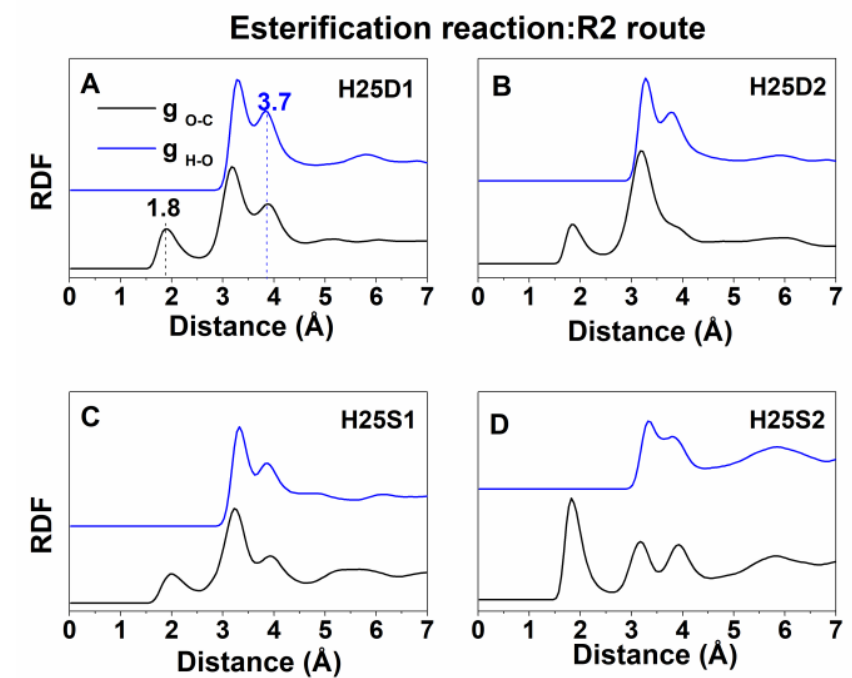

Esterification reaction: $\mathbf{R} 1$ route
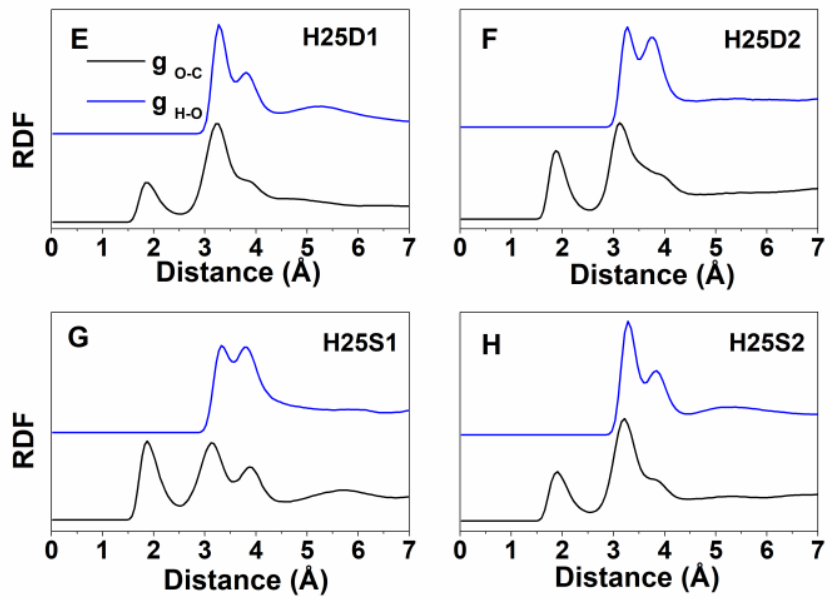

Figure S8. Radial distribution function (RDF) of the $\mathrm{COOH}$ and $\mathrm{OH} 1$ groups (route 1) and the $\mathrm{COOH}$ and $\mathrm{OH} 2$ groups (route 2). (A), (B), (C) and (D) possible ER on route R1. (E), (F), (G) and $(\mathrm{H})$ possible ER on route $\mathrm{R} 2$. 